\title{
Nucleic acid binding agents exert local toxic effects on neurites via a non-nuclear mechanism
}

\author{
Sokhon Pin, ${ }^{*}$ Huiling Chen, $†$ Pamela J. Lein $\ddagger$ and Michael M. Wang $\S$ \\ *Department of Anesthesiology/Critical Care Medicine, Johns Hopkins University, Baltimore, Maryland, USA \\ $\dagger$ Children's Research Institute, Washington DC, USA \\ $\$$ Center for Research on Occupational and Environmental Toxicology, Oregon Health and Science University, Portland, Oregon, USA \\ $\S$ Departments of Neurology and Molecular and Integrative Physiology, University of Michigan, Ann Arbor, Michigan, USA
}

\begin{abstract}
The mechanism by which drugs that target nucleic acids cause neurotoxicity is not well described. We characterized the neurotoxicity of Hoechst 33342 (bis-benzimide), a common cell permeable nuclear dye, in primary neuronal cultures. The mechanism of cell death was not apoptotic, as death is rapid, not accompanied by typical nuclear morphological changes, and is insensitive to inhibitors of transcription, translation and caspase activity. In addition, free-radical scavenging agents failed to attenuate cell death, and damage was not accompanied by mitochondrial dysfunction. Neuronal processes of cells exposed to Hoechst 33342 display dramatic fragmentation prior to cell death. When this compound was applied selectively to the distal axons of sympathetic neurons grown in compartmented cultures, the distal axons
\end{abstract}

were destroyed. However, the proximal processes present in the cell body compartment were spared, demonstrating direct axonal toxicity rather than a remote effect of nuclear dysfunction. Other cell-permeable nucleic acid binding dyes similarly caused rapid dendritic and axonal toxicity. The hypothesis that these nucleic acid binding dyes target RNA localized to dendrites and axons is supported by observations that RNaseV1 induced similar, rapid neurite fragmentation. We conclude that the neurotoxic effects of nucleic acid binding compounds are mediated, at least in part, by direct neurite injury, which does not require involvement of the cell body and nucleus.

Keywords: cortical neurons, Hoechst, neurite, neurotoxicity, nucleic acid dyes, RNase.

J. Neurochem. (2006) 96, 1253-1266.
A large variety of pharmaceuticals have neurological sideeffects and cause neuronal damage. Yet, in most cases, the precise mechanisms of how these diverse compounds cause neuronal injury remain elusive. Compounds which interact with nucleic acids or nucleic acid metabolism frequently affect the nervous system. For example, the chemotherapeutic agent cytosine arabinoside causes confusion, seizures, and cerebellar dysfunction (Resar et al. 1993). Several drugs that are used for cancer are associated with peripheral neuropathies, including chorambucil (Druker et al. 1989), isofosfamide (Patel et al. 1994; Frisk et al. 2001), cis-platin (Ozols and Young 1985), and etoposide (Imrie et al. 1994). Finally, dideoxy nucleoside analogues used for the treatment of HIV commonly result in peripheral neuropathy (Dubinsky et al. 1989; Dalakas 2001).

These drugs are useful clinically because they target DNA synthesis, which is crucial for the growth of tumor cells and viral replication. Cytosine arabinoside is a nucleotide analogue which inhibits DNA synthesis (Slapak et al. 1985). Chlorambucil and isofosfamide are alkylating agents (Kundu et al. 1994; Povirk and Shuker 1994; Fleming 1997) which are capable of modifying DNA and inhibiting DNA replication and transcription. Cis-platin directly binds to DNA and is thought to target DNA synthesis (Wang and Lippard 2005). Etoposide inhibits DNA topoisomerase II, which is crucial for DNA synthesis and repair (Meresse et al. 2004). Finally, HIV dideoxynucleosides impair reverse transcriptase, and therefore inhibit replication of the virus

Received June 6, 2005; revised manuscript received October 3, 2005; accepted October 19, 2005.

Address correspondence and reprint requests to Michael Wang, 7629 Medical Sci II Box 0622, 1137 Catherine St., Ann Arbor, MI 48109-0622, USA. E-mail: micwang@umich.edu

Abbreviations used: GFP, green fluorescent protein; PI, propidium iodide; TMRM, tetramethylrhodamine methylester. 
(De Clercq 2002). It is widely accepted that these agents impair normal stability and/or replication of DNA, resulting in cell cycle disruption, apoptosis or inhibition of viral replication. However, in post-mitotic neurons, the mechanism of action of these agents in causing cellular damage is unclear, as these cells do not depend on DNA replication for survival. Several toxic mechanisms of action of have been proposed, including direct inhibition of DNA stability resulting in programmed cell death via multiple pathways (Park et al. 1998; Stefanis et al. 1999). Yet other studies have suggested neurotoxic compounds influence novel, nonnuclear biochemical pathways (Wallace and Johnson 1989; Martin et al. 1990). Nucleoside analogues have been shown to inhibit mitochondrial DNA synthesis (Cui et al. 1997) which may result in axonal energy failure and neurite dysfunction. In addition, recent studies of DRG neurons exposed to dideoxy drugs demonstrate neurite damage as a result of mitochondrial dysfunction on a timescale much faster than could be accounted for by mitochondrial DNA damage (Keswani et al. 2003), implicating non-nucleic acid mitochondrial toxicity. Overall, given the chemical diversity of these compounds and the multifactorial susceptibility of neurons, it is expected that the neurological side-effects of the many drugs in use are a result of multiple, diverse mechanisms.

This study demonstrates an additional mechanism by which nucleic acid binding compounds induce neuronal injury. We report the neurotoxic properties of the nucleic acid binding agent Hoechst 33342, a cell-permeable dye used to label live cell nuclei. Curiously, in contrast to the slower actions of genotoxic compounds in non-neuronal cells, Hoechst 33342 induces extremely rapid morphological changes in neurites marked by fragmentation and blebbing of axons and dendrites. We find that Hoechst 33342 mediates toxicity through non-nuclear actions and further demonstrate that a variety of other nucleic binding agents mediate similar rapid neuronal damage. The morphological changes seen with nucleic acid binding compounds is mimicked by treatment with RNaseV1, suggesting that RNA may be an essential component of neurite homeostasis and that neuronal damage through nucleic acid binding drugs could be mediated by actions on neurite RNA.

\section{Materials and methods}

\section{Cell culture}

All animals were handled in accordance with established national and institutional guidelines under the auspices of the animal care and use committee. HEK293A cells (Qbiogene, Irvine, CA, USA) were grown as described in Dulbecco's modified Eagle's medium containing 10\% fetal bovine serum (Xu et al. 2003). Mouse cortical cultures were prepared from E18 embryos and plated on poly D-lysine-treated dishes in neurobasal/B27 media using established protocols (Brewer 1995; Xu et al. 2003). Immunohistochemical analysis has demonstrated that our cultures are more than $99 \%$ neuronal. Experiments shown were performed on immature neurons (days in vitro 3-5) prior to the onset of glutamate sensitivity. Cells were transfected with pEGFP plasmids from Clontech (San Jose, CA, USA) using Lipofectamine 2000 (Xu et al. 2003). For viability studies, cells were usually pretreated with DNaseI $(10-20 \mu \mathrm{g} / \mathrm{mL}$ for 2-6 $\mathrm{h}$ followed by media replacement) before addition of drugs to decrease background counting of dead cells in the culture. Livedead assays were performed using calcein AM and propidium iodide (PI) (Molecular Probes, Eugene, OR, USA); live cells metabolize calcein AM and fluoresce green, while dead cells fluoresce red because of PI access to the nucleus. Cells were imaged and photographed using an inverted Nikon TE200 equipped with a Spot RT digital camera. For time-course studies, cells were grown in HEPES-buffered media in an enclosed chamber on the microscope stage which was heated to $37^{\circ} \mathrm{C}$. At least four different high powered $(40 \times)$ fields were photographed, and then manually counted. Morphological changes in axons and dendrites (collectively referred to as neurites) were scored in a blinded fashion. A neuron was scored as exhibiting significant neuritic damage if more than one axonal or dendritic process had at least three regions of distinct blebbing or fragmentation along its length. In general, if a neuron had one damaged neurite, almost all of the processes, including dendrites and axons, were damaged. Nuclear morphology was also analyzed blinded using established criteria for apoptosis (Stefanis et al. 1999). Data from all groups represent at least three wells of cultures and each experiment was performed three times to validate consistency between cultures.

\section{Culture of sympathetic neurons in compartmented Campenot} chambers

Compartmented Campenot chambers were set up as described by Senger and Campenot (1997). Briefly, 35-mm dishes were precoated with a layer of ammoniated rat tail collagen $(0.75 \mathrm{mg} / \mathrm{mL})$, followed by a layer of air-dried rat tail collagen supplemented with laminin $(10 \mu \mathrm{g} / \mathrm{mL})$. Three-compartmented Teflon dividers (Camp10, Tyler Research Instruments, Edmonton, AB, Canada) were seated on top of parallel tracks scratched in the collagen substrate with a pin rake (Tyler Research Instruments) and secured in place with silicone vacuum grease (Dow Corning, Huntington Beach, CA, USA). Integrity of the grease seals was assessed by placing culture medium into the side chambers only and incubating the chambers overnight in a $37^{\circ} \mathrm{C}$ incubator. Only chambers that did not leak were used in subsequent experiments. Medium was removed from side compartments and dissociated sympathetic neurons were plated in the center compartment in serum-free medium (Dulbecco's modified Eagle's medium/F12 with N2 supplement) containing nerve growth factor $(100 \mathrm{ng} / \mathrm{mL}$, Harlan Bioproducts, Madison, WI, USA). Sympathetic neurons were dissociated from the superior cervical ganglia of embryonic day 21 or post-natal day 1-2 Holtzmann rats (Harlan SpragueDawley, Rockford, IL, USA) according to previously described methods (Lein and Higgins 1989). The next day the integrity of the seals between the compartments was reconfirmed by checking for leakage from the compartment containing the cell suspension into the adjacent compartments. Culture medium then was added to the compartments not containing cells of those culture dishes exhibiting 
intact seals between compartments, and cytosine-arabinoside (1 $\mu \mathrm{M})$ was added to the medium in the compartment containing the cell bodies for $48 \mathrm{~h}$ to eliminate non-neuronal cells. After axons had extended through the grease seals into the adjacent compartments (5-7 d after plating), nerve growth factor was withdrawn from the compartment containing cell bodies but was maintained in the adjacent compartments to encourage growth of axons into the adjacent compartments and to eliminate neurons that had failed to extend axons through the grease seals. Experiments were initiated when there was significant neurite outgrowth in the adjacent compartments (10-14 d after plating).

\section{Reagents}

All drugs and chemicals were obtained from Sigma (St Louis, MO, USA), unless noted. Cell culture media were from Invitrogen (Carlsbad, CA, USA). Fluorescent probes were obtained from Molecular Probes. Biochemical grade RNaseV1 and purified tRNA were purchased from Ambion (Austin, TX, USA).

\section{Statistical analyses}

Data is presented from representative experiments, which were repeated at least three times. Standard error bars are shown which represent cell counts from three wells of cells treated in identical fashion.

\section{Results}

\section{Cell death induced by nucleic acid binding dyes}

Hoechst 33342 is a commonly used nucleic acid binding dye, which is highly cell permeable. Because of these properties, it has been used to label nuclei of live cells for cell sorting, tracking, and for analysis of nuclear morphology. Although Hoechst 33342 has been shown to induce apoptosis in HL-60 and BC3H-1 cells (Zhang and Kiechle 1997; Zhang et al. 1999), its effect on primary neurons has not been characterized. In initial experiments, we found that Hoechst 33342 causes rapid concentration-dependent toxicity in cultured murine cortical neurons (Figs 1a and c). Neurons were significantly more sensitive to the toxic effects of Hoechst 33342 relative to non-neuronal cells (Figs $1 \mathrm{~b}$ and $\mathrm{d}$ ).

\section{Non-apoptotic mechanism of Hoechst 33342 cell death} Several lines of evidence suggest that Hoechst 33342 may cause neuronal cell death via apoptosis. First, Hoechst has been shown to cause apoptosis in HL-60, BC3H-1 myocytes, H4-II-E-C3 rat hepatoma cells, HT-114 melanoma cells, and human skin fibroblasts (Zhang and Kiechle 1997; Zhang et al. 1999; Kiechle 2002). Second, Hoechst 33342 not only binds to minor grooves in DNA, but also inhibits topoisomerase I, and other agents that inhibit this enzyme, including camptothecin, cause neuronal apoptosis (Morris and Geller 1996). To determine if Hoechst 33342 similarly induces apoptosis in cultured cortical neurons, we compared the effects of Hoechst 33342 and camptothecin on nuclear morphology.
Nuclei of cortical neurons treated with camptothecin for $24 \mathrm{~h}$ appeared shrunken, blebbed and fragmented (Fig. 2a), which is characteristic of cells undergoing apoptosis (Stefanis 1999). In contrast, nuclei of cortical neurons treated with Hoechst 33342 for $24 \mathrm{~h}$ appeared round and intact (Fig. 2b) and did not exhibit the morphological characteristics of nuclei undergoing programmed cell death. Actinomycin D and cycloheximide, inhibitors of RNA and protein synthesis, respectively, failed to attenuate Hoechst 33342induced cell death (Figs 2c and d). In addition, DNA isolated from cells treated with Hoechst 33342 did not demonstrate fragmentation, as seen with camptothecin treatment (Fig. 2e), although there was a slight apparent change in mobility in Hoechst-treated DNA, which could have been the result of infrequent nicking of DNA or of a change in mobility induced by dye intercalation. In total, we found no evidence that Hoechst 33342 acts by programmed cell death as determined by a variety of established markers of apoptosis.

\section{Morphological effects of nuclei acid binding dyes in neurites}

To investigate the morphological effects of Hoechst 33342 on cortical neurons, we transfected neurons with a green fluorescent protein (GFP) expression plasmid prior to adding the drug. This enabled us to visualize the effects of Hoechst 33342 over time on individual cells. Nearly all neurons displayed striking morphological changes marked by progressive blebbing and fragmentation of the neurite (Fig. 3a). Hoechst 33342 caused similar morphological changes in neurons grown in low-density cultures that were loaded with the fluorescent vital dye calcein AM (not shown). Hoechst 33342 does not induce these rapid morphological changes by inhibition of topoisomerase I, as camptothecin failed to induce similar morphologic changes (Fig. 3b). The response was rapid, as all cells displayed abnormal morphology after 30 min of $30 \mu \mathrm{M}$ Hoechst 33342 (Fig. 3c).

Next, we examined whether other cell permeable nucleic acid binding compounds exhibited similar properties as Hoechst 33342. Indeed, a large number of dyes were able to induce visible neurite morphological changes in a rapid time frame at micromolar concentrations (Fig. 4). Of note, nonpermeant dyes such as propidium iodide failed to elicit rapid neurite damage (not shown).

\section{Hoechst 33342 death mechanism is independent of free radical formation and mitochondrial stress}

Neurons are extremely sensitive to free radical-induced cell death. We therefore tested whether free radical scavengers could attenuate cell death induced by Hoechst 33342 . Free radical-mediated mechanisms appear to be unlikely as scavengers such as phenyl-tert-butylnitrone (Gould and Bickford 1994; Sturgess et al. 2000; Fig. 5) failed to attenuate Hoechst 33342 toxicity. 


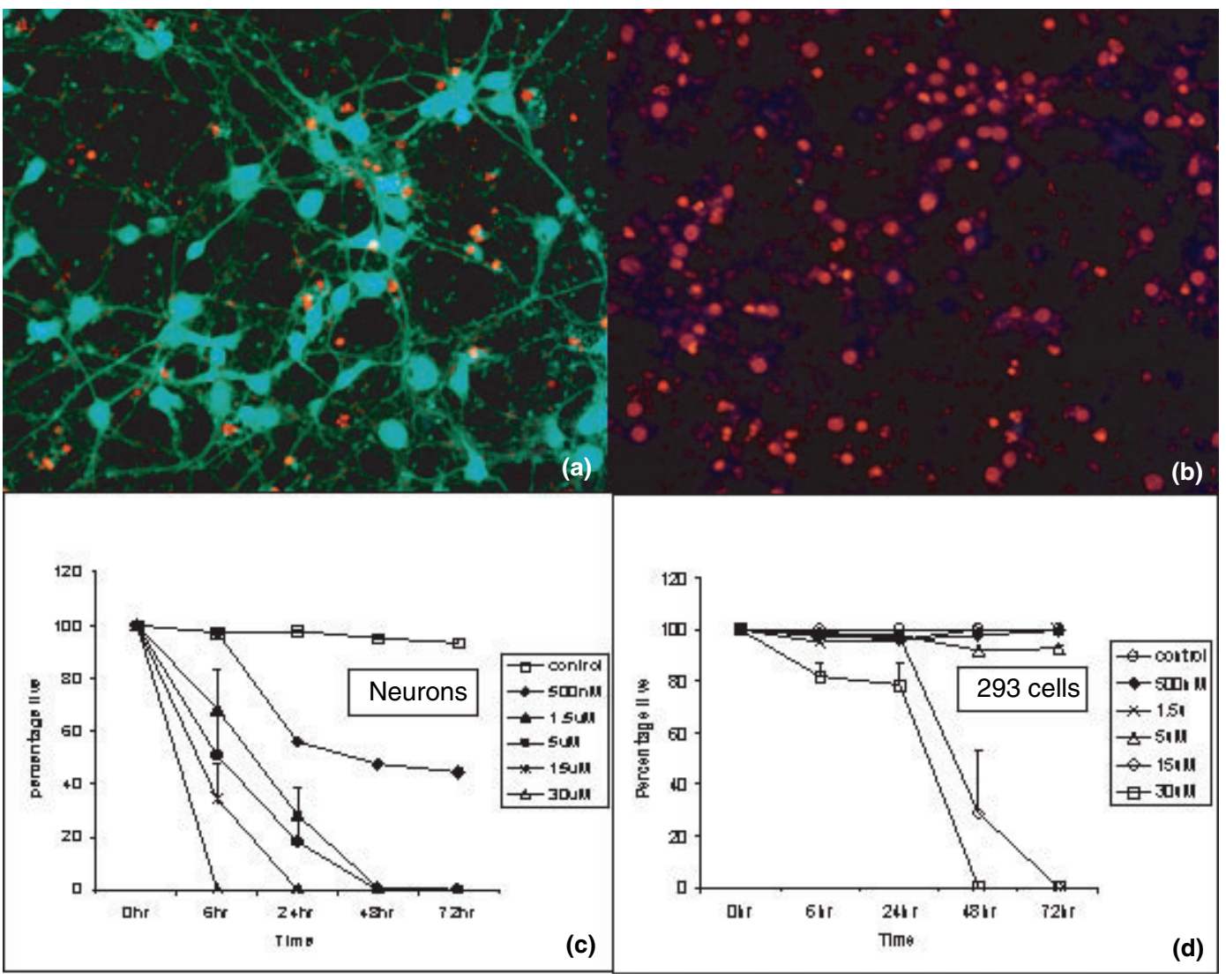

Fig. 1 Hoechst 33342 causes rapid, concentration-dependent neurotoxic effects in primary cultures of cortical neurons. (a) Untreated cortical cultures show intense green fluorescence of calcein AM viability dye and a modest uptake of propidium iodide (red fluorescence), which marks dead cells. These cells were not pretreated with DNasel. (b) After $24 \mathrm{~h}$ of treatment with $15 \mu \mathrm{m}$ Hoechst 33342, all cells are dead. (c) Quantitative analysis of the ratio of viable to non-viable cells in cortical cultures demonstrates concentration dependent toxicity of Hoechst 33342. (d) 293A cell lines are much less sensitive to Hoechst 33342. Cells used in quantitative analysis were pretreated with DNasel (before Hoechst treatment) to reduce the background of cells which had already died before addition of Hoechst 33342. Data are represented as the mean \pm SEM from three identically treated wells. Experiments were repeated with similar outcomes at least three times.
Another important determinant of neurite integrity is mitochondrial stability. We thus assessed whether the morphological changes seen in response to Hoechst 33342 could be linked to mitochondrial toxicity (Fig. 6). To determine whether mitochondrial stress could play a role in Hoechst 33342 neurite toxicity, we loaded cells with tetramethylrhodamine methylester (TMRM) (Nieminen et al. 1995; Ward et al. 2000) to determine whether loss of mitochondrial membrane potentials preceded neurite fragmentation. It has been previously reported that acute exposures to Hoechst 33342 cause a transient mitochondrial depolarization in HL-60 cells (Chen et al. 2004). Similarly, we observed a $50 \%$ reduction in TMRM fluorescence in cortical neurons $15 \mathrm{~min}$ after adding $\mathrm{H} 33342$ at $60 \mu \mathrm{M}$, but TMRM fluorescence returned to control levels within $30 \mathrm{~min}$ (unpublished data). However, mitochondrial potentials were unaffected at early time points when exposed to Hoechst 33342 at lower concentrations $(15 \mu \mathrm{M})$ that cause neurite fragmentation. In fact, the mitochondrial signal persisted long after initial signs of neurite fragmentation and blebbing, suggesting that mitochondrial injury does not play a significant role in neurite instability. Therefore, progressive changes to the mitochondria, at least at this level, do not appear to correlate with neurite damage. Analysis of the TMRM fluorescence in neurites was compared with cell body fluorescence to discern potential differences in neurite versus cell body mitochondria (not shown). This analysis failed to demonstrate evidence of neurite mitochondrial dysfunction prior to appearance of morphological changes.

\section{Role of excitotoxicity in Hoechst 33342-induced neurite changes}

Neurites can be damaged by excitotoxic injury and display characteristic changes that are remarkably similar to those induced by Hoechst 33342, with fragmentation, swelling 

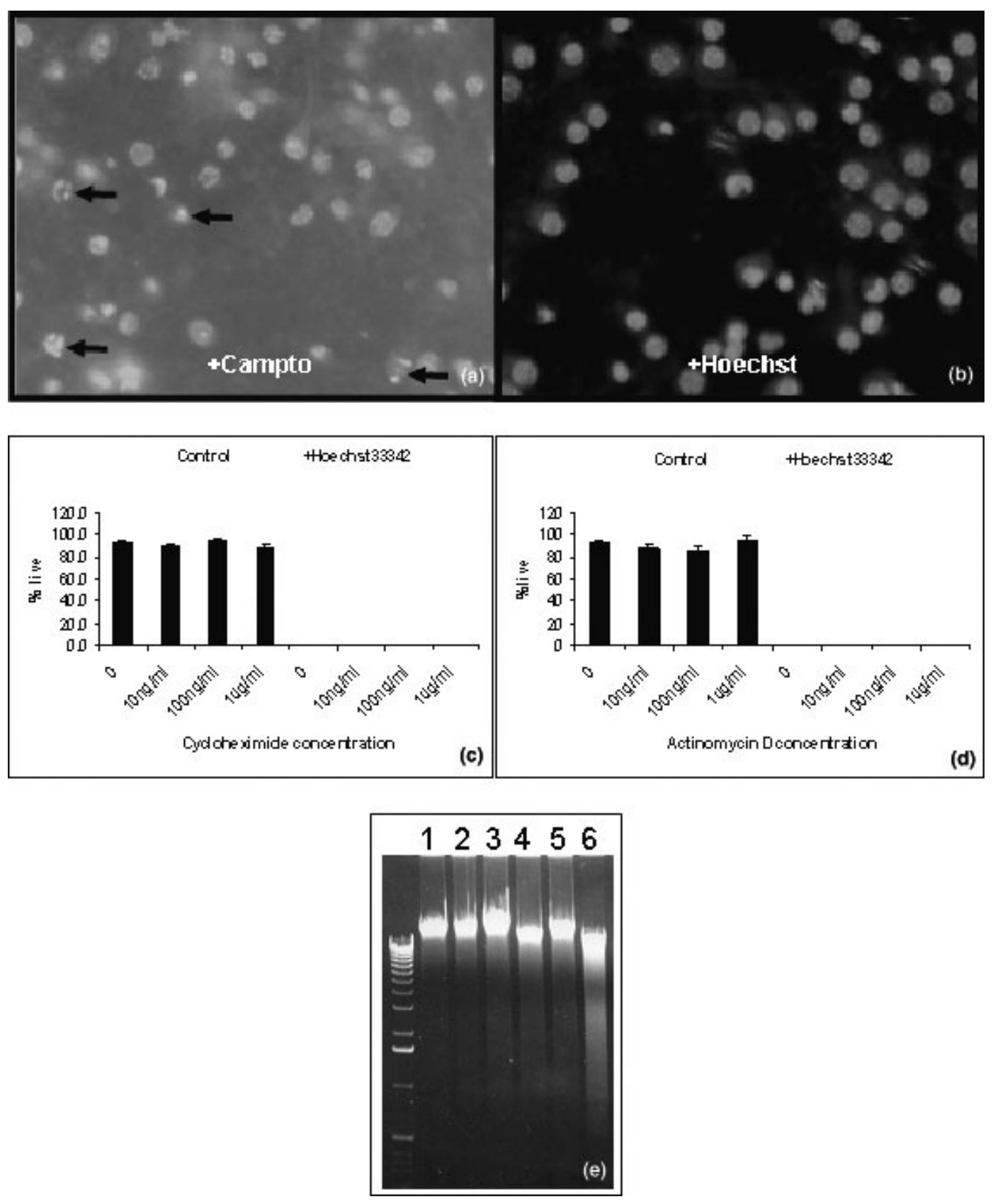

Fig. 2 Non-apoptotic mechanism of neuronal cell death in cortical neurons treated with Hoechst 33342. (a) Nuclear morphology of cortical neurons treated with camptothecin ( $800 \mathrm{~nm}$ for $24 \mathrm{~h}$ ) then stained with Hoechst 33342 for 30 min to visualize chromatin in nuclei. Note the appearance of multiple fragmented and bright nuclei with evidence of nuclear condensation (see arrows). (b) Cells treated with $15 \mu \mathrm{m}$ Hoechst 33342 overnight display round nuclei with no evidence of fragmentation and condensation. A series of cultures were treated with cycloheximide (c) or actinomycin D (d) at indicated concentrations overnight. Control cells (white bar on the left) and Hoechst 33342

and blebbing seen within minutes of NMDA application (Park et al. 1996). Although the neurons used in this study were immature and resistant to glutamate toxicity, we treated cells (four bars on the right) were scored for viability after $24 \mathrm{~h}$ using calcein $\mathrm{AM}$ and PI fluorescence. Neither cycloheximide nor actinomycin D blocked the ability of Hoechst 33342 to induce cell death. (e) Cortical neurons were treated with medium alone (lane 1), medium supplemented with Hoechst 33342 for 20 min (lane 2), $2 \mathrm{~h}$ (lane 3), or $24 \mathrm{~h}$ (lane 4), or medium supplemented with camptothecin (800 nM) for $2 \mathrm{~h}$ (lane 5) or $24 \mathrm{~h}$ (lane 6). Genomic DNA was analyzed on an agarose gel to assess DNA fragmentation, which is an indicator of programmed cell death. (c, d) Data are represented as the mean \pm SEM (three wells per group).

performed experiments to determine if blocking excitotoxic pathways was sufficient to attenuate Hoechst 33342 toxicity (Fig. 7). Excitotoxicity depends on activation of 
(a)

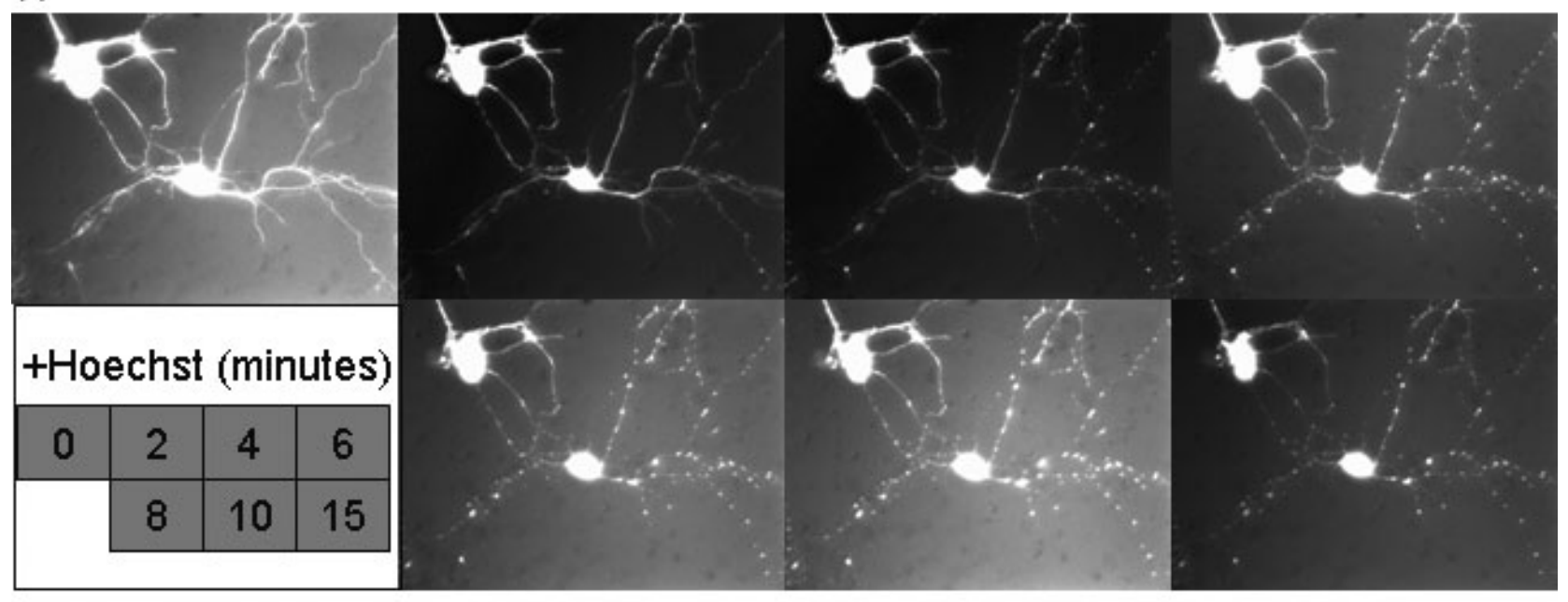

(b)

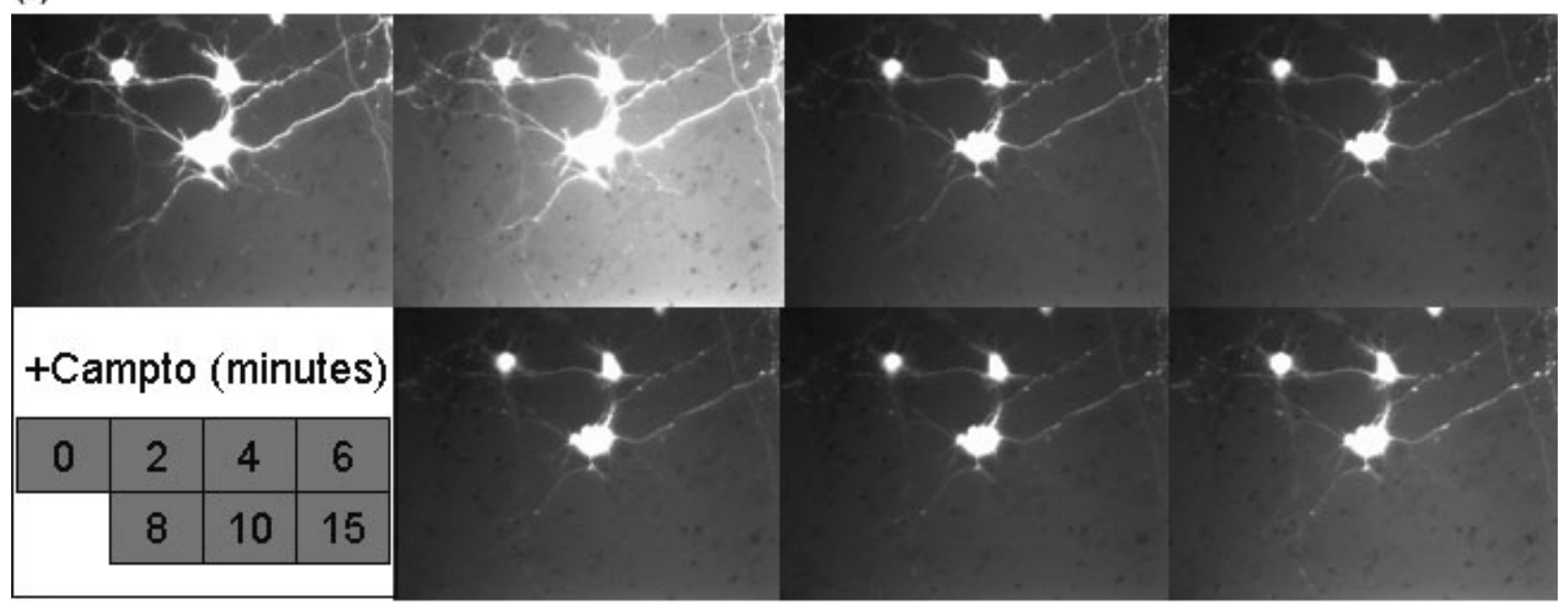

(c)

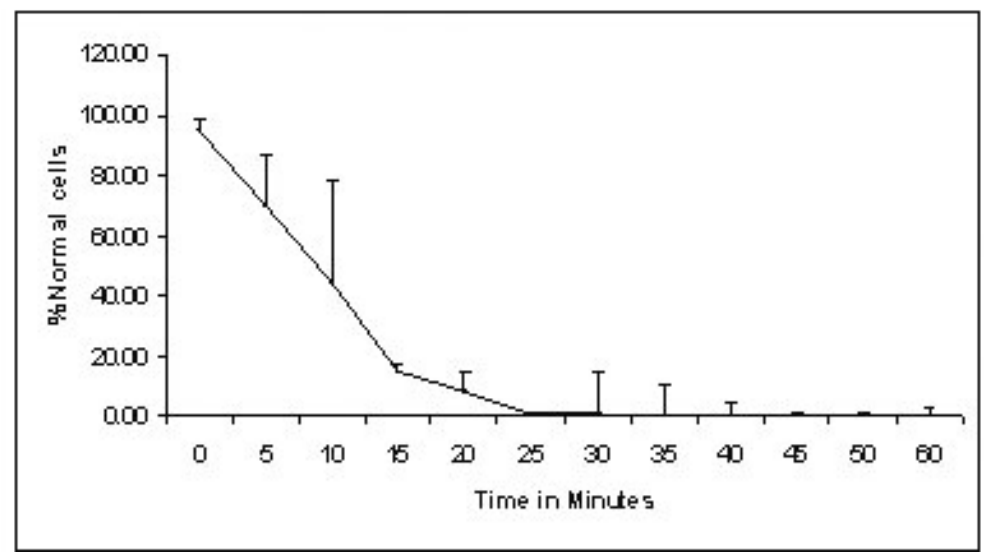

Fig. 3 Temporal analyses of neurite fragmentation in response to Hoechst 33342. Sequential images of GFP-transfected neurons (in min) after treatment with $15 \mu \mathrm{m}$ Hoechst 33342 (a) or camptothecin
(800 nм) (b). (c) Percentage of GFP-transfected neurons with neurite fragmentation after different times of exposure to $15 \mu \mathrm{M}$ Hoechst 33342 . 
(a)
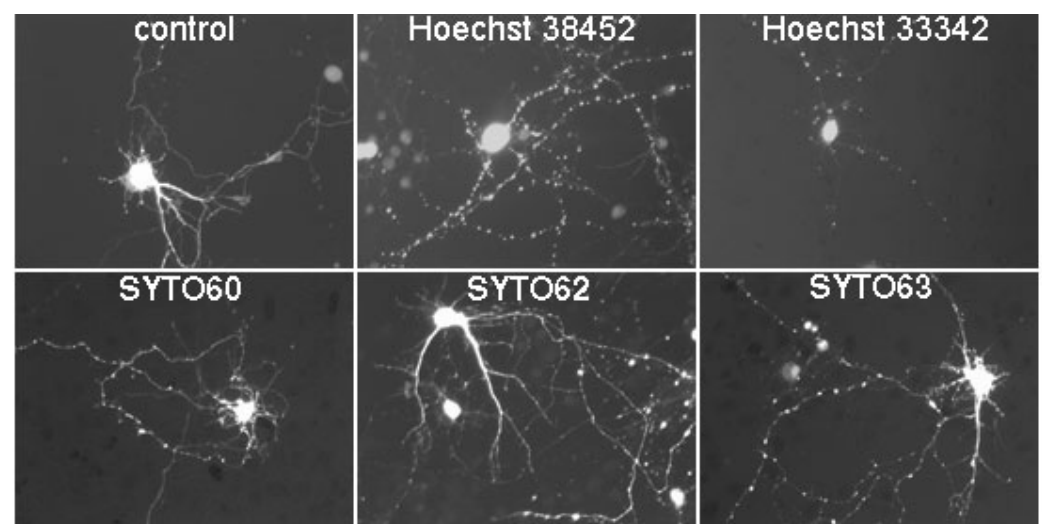

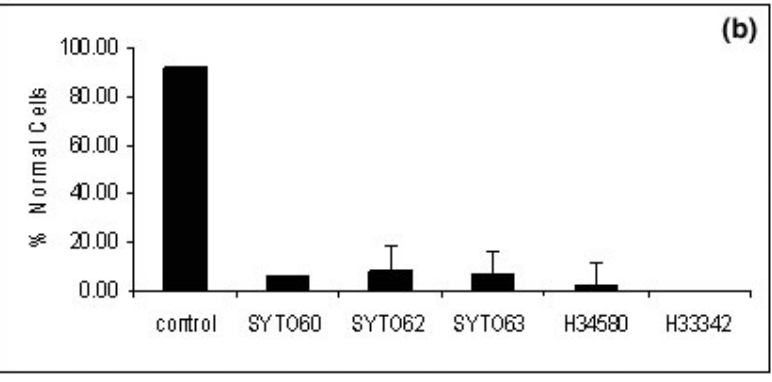

Fig. 4 Toxicity of cell-permeable nucleic acid dyes. (a) Exposure of GFP-transfected cortical neurons to a selection of nucleic acid binding dyes resulted in rapid morphological changes in neurites $(1 \mathrm{~h})$; dyes were used at $15 \mu \mathrm{m}$. (b, c) Quantitative analysis of neurite toxicity of

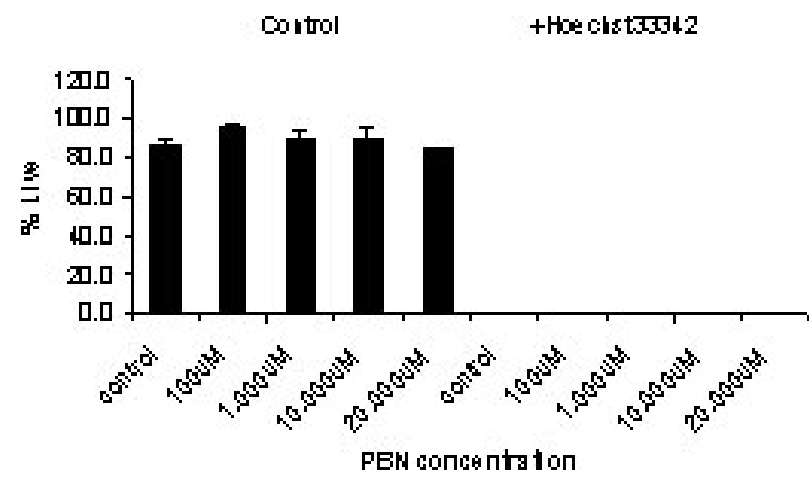

Fig. 5 Hoechst 33342 causes neurotoxicity via a free radical-independent mechanism. Cortical cultures were treated overnight with the free radical scavenger phenyl-tert-butylnitrone at varying concentrations. Control cells (five bars on the left) and Hoechst 33342 (five bars on the right) -treated cells were scored for viability using calcein AM and PI fluorescence after $24 \mathrm{~h}$.

voltage-sensitive sodium channels and calcium influx through both voltage-sensitive calcium changes and glutamate receptors (Hasbani et al. 1998). As shown in Fig. 7, blocking voltage-gated sodium channels with TTX $(1 \mu \mathrm{M})$, did not alter the toxic effects of Hoechst 33342 on neurite morphology. Similarly, sequestration of extracellular calcium by EDTA, or blocking of calcium influx

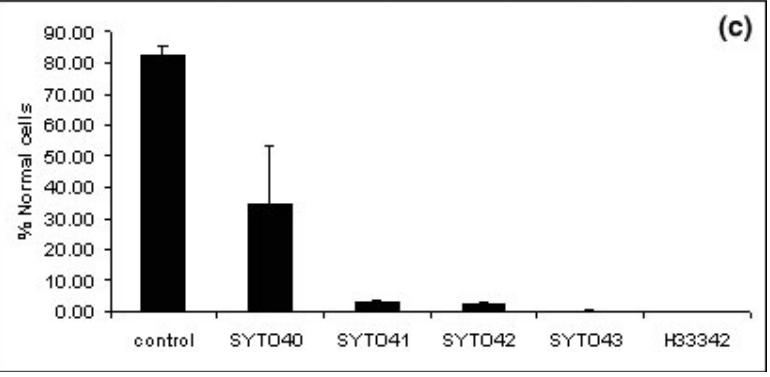

cortical neurons treated with a set of cell permeable nucleic acid dyes; criteria for neurite abnormality are described in the Materials and methods.

through glutamate receptors by the glutamate receptor antagonists MK801 and NBQX failed to block the morphological changes seen with Hoechst 33342.

\section{Toxicity of Hoechst 33342 on isolated axons}

The rapid toxicity to neurites could involve direct action on the neurite, and/or an indirect action on the cell body, which then signals to the axonal and dendritic processes. To distinguish between these mechanisms, we examined the effect of Hoechst 33342 on sympathetic neurons grown in compartmented cultures (Senger and Campenot 1997). Addition of Hoechst 33342 to one of the two compartments containing distal axons resulted in progressive degeneration of axonal morphology within that compartment only (Figs 8a and b). Axonal fragmentation was not observed in the compartment containing cell bodies and proximal processes, nor was it observed in the second compartment containing distal axons that were not exposed directly to Hoechst 33342. Similarly, degeneration of processes was also seen when the drug was added to the chamber containing cell bodies and proximal axons; however, distal axons not in direct contact with drugs maintained normal morphology (Fig. 8c). These results demonstrated that Hoechst 33342 causes local, direct toxic effects on axons in vitro, and that this toxicity is not dependent on interactions with nuclear DNA. 


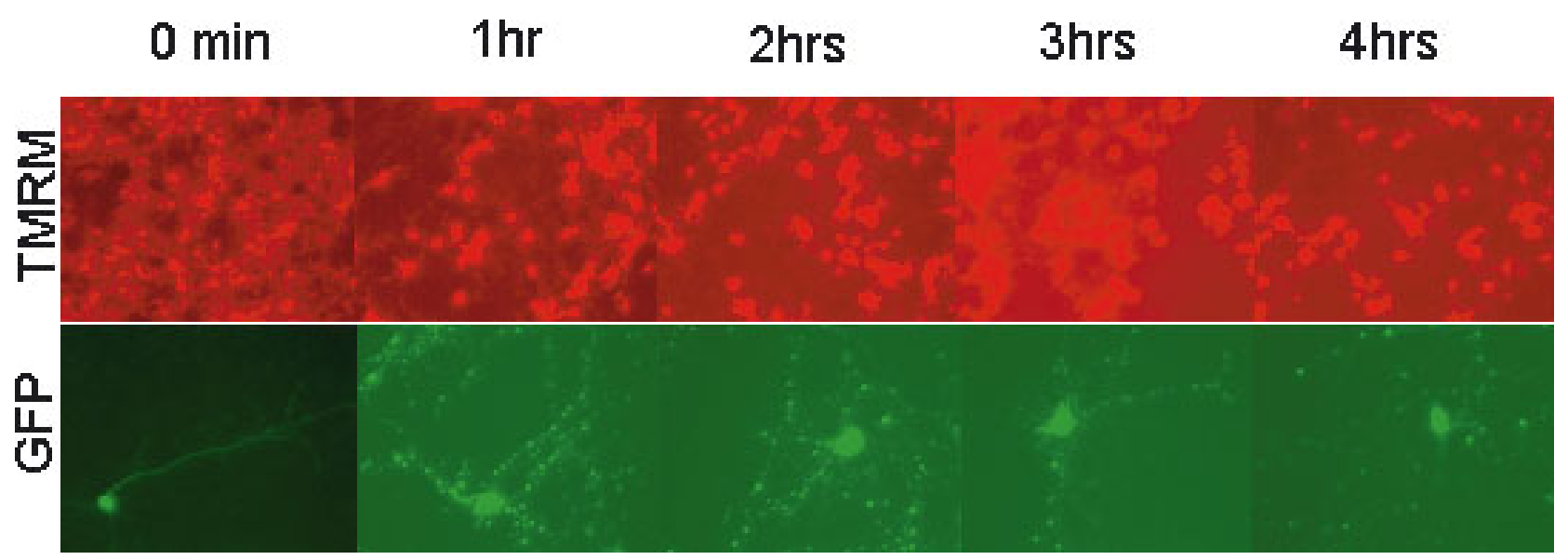

Fig. 6 Toxicity of Hoechst 33342 is not caused by persistent mitochondrial failure. Neurons were exposed to $15 \mu \mathrm{m}$ Hoechst 33342 for varying periods of time (top row). Thirty minutes before each time point, cells were labeled with the mitotracker dye TMRM (200 nM for 30 prior to end of time point) and photographed to assess the functional status of mitochondria (maintenance of normal mitochondrial electrical potential is indicated by the fluorescence of TMRM). Photographs were

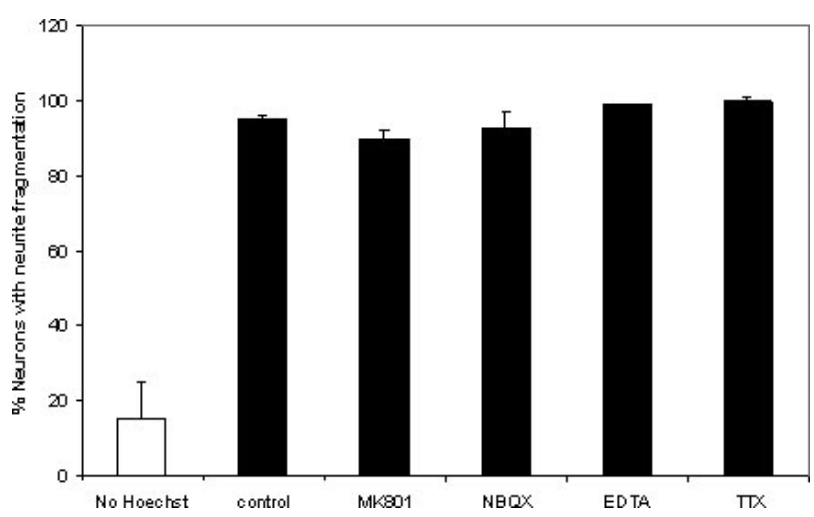

Fig. 7 Hoechst 33342 does not cause neurite injury via excitotoxic mechanisms. GFP-transfected neurons were scored for neurite fragmentation. The first bar (white) shows the baseline fragmentation in the absence of Hoechst 33342 . The remaining bars (black) show the effect of $1 \mathrm{~h}$ of $15 \mu \mathrm{m}$ Hoechst 33342 treatment. Bars 3-6 show neurite fragmentation by Hoechst 33342 in neurons pre-incubated (60 min) with drugs that block glutamate receptors (MK801 $20 \mu \mathrm{M}$, NBQX $30 \mu \mathrm{m}$ ), calcium influx (EDTA $1 \mathrm{~mm}$ ), or voltage-gated sodium channels $(\mathrm{TTX}, 10 \mu \mathrm{M})$. Data are represented as the mean \pm SEM ( $n=3$ per experimental condition).

\section{Toxicity of RNaseV1 on neurites}

RNA is present in the neurites of neurons (Knowles et al. 1996; Job and Eberwine 2001). RNA frequently adopts secondary structure involving inter- and intramolecular base pairing, which confers it with common chemical properties with DNA. Consequently, RNA and DNA share affinity for most nucleic acid binding drugs, including Hoechst 33342 obtained with constant exposure settings. To prevent possible photobleaching of TMRM or light-induced damage to cultures, all cells were processed in the dark and exposure to excitation light was limited to the time required to focus and obtain the photograph. In parallel experiments using sister cultures; representative GFP-transfected neurons were photographed to document potency of Hoechst 33342 in neurite fragmentation as a function of time (bottom row).

dyes (Wilson et al. 1993; Dassonneville et al. 1997) and the SYTO compounds (Molecular Probes) (Knowles et al. 1996). Therefore, the neurotoxicity of nucleic acid binding compounds could potentially be mediated by interactions with RNA, rather than DNA. As most nucleic acid probes do not distinguish between RNA and DNA, we assessed the effect of RNaseV, an endonuclease that specifically targets double-stranded RNA (Lockard and Kumar 1981; Lowman and Draper 1986), on neurite morphology. As demonstrated in Fig. 9( $a$ and b), incubation of this enzyme with cortical neurons causes rapid morphological changes in neurites that are comparable with those observed with Hoechst 33342 over the same time period (results with RNaseV1 are quantified in Fig. 9e). The enzymatic action of RNase can be inhibited by heparin or tRNA (Mahalakshmi et al. 2000), and pre-incubation of cortical cultures with either heparin or tRNA (Mahalakshmi et al. 2000) completely blocked the RNaseV1-induced changes in neurite morphology, suggesting that the cytotoxic actions of RNase were mediated by its RNA degradation function (Figs 9c and d; results are quantified in Fig. 9f). In addition, heat treatment of RNaseV1 strongly inhibited its toxic effects in cortical neurons (Fig. 9g), suggesting that an enzymatic component rather than a small chemical contaminant from the preparations, mediated RNaseV1 neurotoxicity.

We next attempted to test whether RNaseV1 was crossing the cell membrane to disrupt RNA. When neurons were treated with RNaseV1, there was an immediate decrease in the amount of total RNA extracted from treated cells at $30 \mathrm{~min}$ (Fig. 9h). There was no further decrease in the amount of RNA for $4 \mathrm{~h}$. However, 


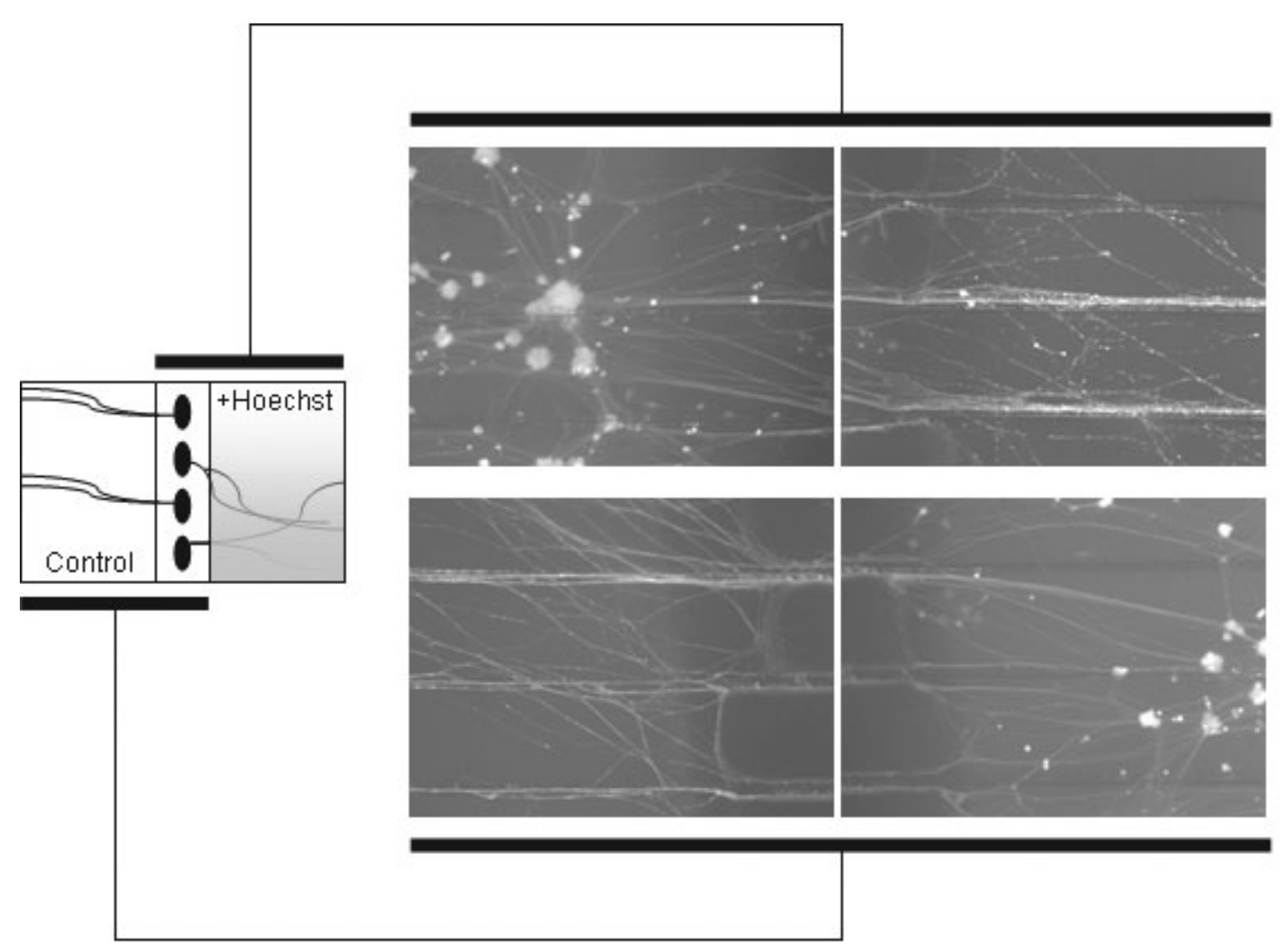

(a)

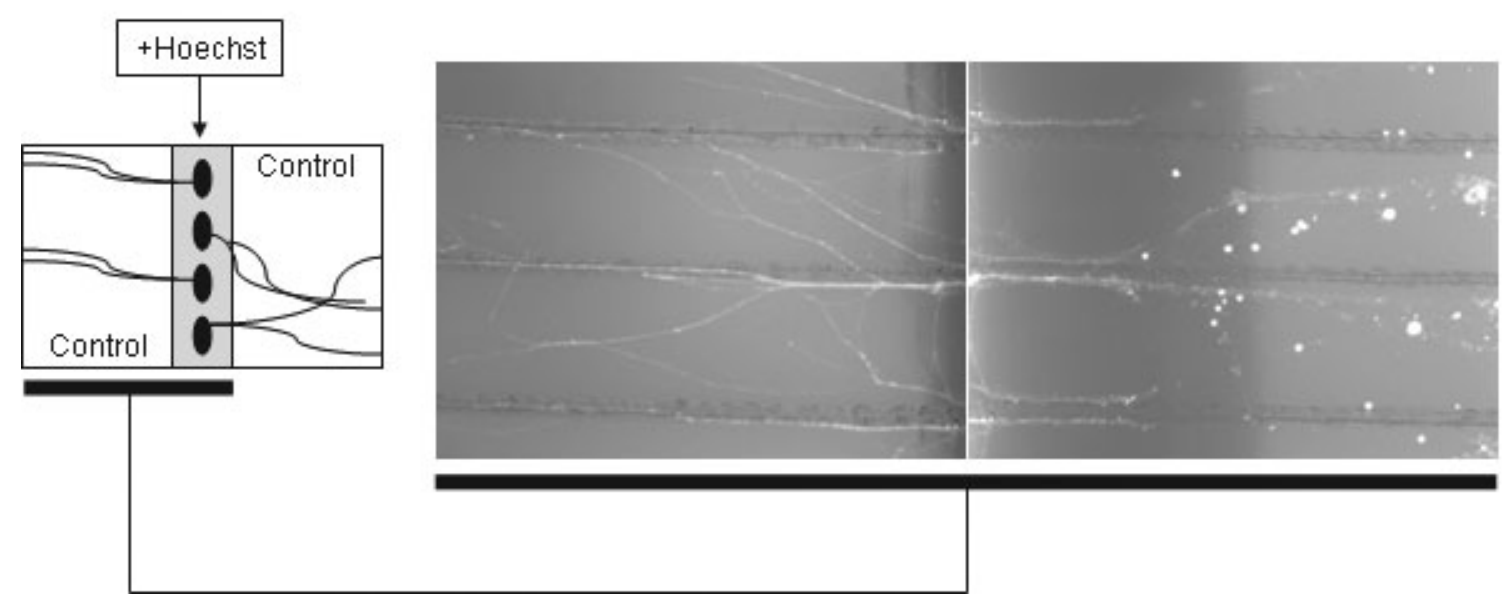

(c)

Fig. 8 Neurite toxicity of Hoechst 33342 is independent of nuclear action. Sympathetic neurons labeled with calcein AM were grown in compartmented chambers (left schematic) which allows physical separation of the medium bathing cell bodies and proximal processes (center compartment) from that bathing distal axons (left and right compartments). In this experiment, Hoechst 33342 (30 $\mu \mathrm{m})$ was added only to the right chamber. (a) Adjacent microscopic fields demonstrate the toxicity of Hoechst 33342 to axons exposed to Hoechst 33342 for

membrane permeability to propidium iodide was seen in parallel cultures only at $4 \mathrm{~h}$ and beyond (Fig. 9i). These data suggest that RNaseV1 is capable of crossing the cell membrane and digesting intracellular RNA, and that this precedes the onset of cell death.
$1 \mathrm{~h}$. Note that the cell bodies are intact. (b) Adjacent microscopic fields demonstrating that control axons and cell bodies in the left and center compartment, which were not exposed to Hoechst 33342 , are intact. (c) Addition of Hoechst 33342 to the center well induced rapid morphological changes in proximal axons within the center chambers. However, the distal axons of the same cells (left and right compartments) remained intact.

\section{Discussion}

Our studies demonstrate unique neurotoxic properties of nucleic acid binding dyes. Although nucleic acid binding dyes have been developed specifically for their nuclear 

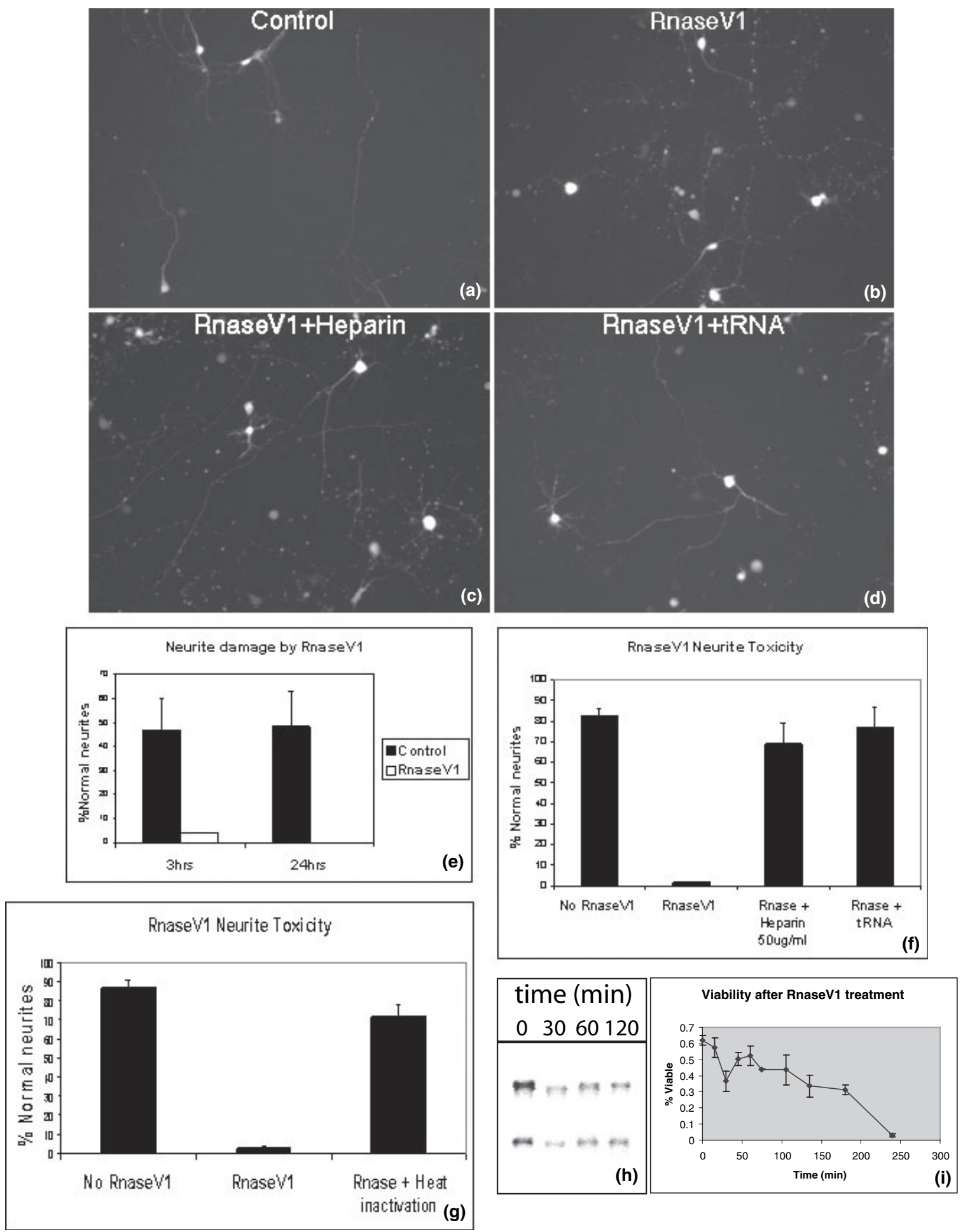

Fig. 9 RNaseV1 causes rapid neurite fragmentation. GFP-transfected cortical neurons were incubated with RNaseV1 (4 units $/ \mathrm{mL}$ ) for $1 \mathrm{~h}$, in the absence or presence of inhibitors of the enzyme. (a) Control neurons exhibit minimal neurite breakdown. (b) Treatment with RNaseV1 causes rapid neurite blebbing and fragmentation. In contrast, incubation of cells with the RNase inhibitors (c) heparin (100 $\mu \mathrm{g} /$ $\mathrm{mL})$ or (d) tRNA $(100 \mu \mathrm{g} / \mathrm{mL})$ attenuated the neurotoxic effects of RNaseV1-induced toxicity. (e) Quantitation of neurite damage induced

by RNaseV 1 at 3 and $24 \mathrm{~h}$ demonstrated uniform cell injury at 1 day. (f) Quantitative analysis of the ability of heparin and tRNA to inhibit the neurite toxicity of RNaseV1. (g) Heat inactivation of RNaseV1 reduces the neurite toxicity of the enzyme. (h) RNaseV1 treatment ( $5 \mathrm{units} / \mathrm{mL}$ ) reduced the amount of rRNA extracted from neurons. (i) This reduction in rRNA preceded the onset of cell death, marked by propidium iodide nuclear fluorescence. Cells were pretreated with DNasel (as in Fig. 1) and live cells remaining were counted using calcein AM fluorescence. 
properties, the neurotoxic properties of these compounds do not appear to involve apoptosis and surprisingly cause direct local neurotoxic effects in neurites via mechanisms that do not involve the cell body or nucleus. Similar neurite damage was observed for a large family of cell permeable nucleic acid binding agents, suggesting a common molecular pathway.

Park et al. (1996) have previously demonstrated the acute morphological changes induced by glutamate in mature cortical cultures. Glutamate-induced changes in neurite morphology are strikingly similar to those we observe in immature cultures exposed to nucleic acid binding dyes. In contrast to these studies, we used immature cortical cultures in which excitotoxicity is not a significant mechanism of death. Therefore, it is not surprising that the mechanism by which these neurons die in response to Hoechst 33342 appears not to involve glutamate toxicity, voltage-sensitive sodium channels, or extracellular calcium, suggesting a neurotoxic mechanism distinct from glutamate-induced toxicity that results in a grossly similar phenotype. Also, in contrast to studies with glutamate, Hoechst 33342 toxicity involves both axons and dendrites, whereas excitotoxininduced neuritic damage has been described only in dendrites (Park et al. 1996). We have shown similar toxic effects of several of these nucleic acid binding compounds in mature, glutamate-sensitive cortical and hippocampal cultures (unpublished data). Combined with our findings that peripheral neurons also demonstrate sensitivity to these agents, we conclude that our results appear to be generalized to multiple neuronal types.

What could account for the exquisite sensitivity of neurites to damage by nucleic acid binding compounds? Although non-nucleic acid-dependent mechanisms are possible, the common dramatic effect of numerous structurally diverse nucleic acid binding agents suggests that these compounds act on neurons through nucleic acid binding. We therefore consider two classes of mechanisms: those involving DNA versus those targeting RNA.

\section{Nuclear DNA}

The most direct evidence arguing against the hypothesis that nucleic acid binding drugs cause neurotoxicity via interactions with nuclear DNA are the experiments using sympathetic neurons grown in compartmented Campenot chambers. Rapid axonal damage was seen only with direct application of nucleic acid binding compounds and did not require application to the nucleus. While there are great similarities in the temporal, quantitative and qualitative nature of the neurite damage observed in response to Hoechst 33342 between sympathetic and cortical neurons in our study, one cannot rule out the possibility that nuclear DNA is involved in Hoechst 33342-mediated cortical neuronal injury. However, this seems unlikely as neurite blebbing and fragmentation is obvious within $10 \mathrm{~min}$ of Hoechst application. This amount of time seems insufficient to allow the sequence of events that would have to occur if DNA were the primary target, e.g. diffusion of the dye through the plasma membrane and nuclear membrane into the nucleus, signaling within the nucleus, and signal transduction from the nucleus to the neurite several hundred microns away. Further evidence arguing against the involvement of nuclear DNA in Hoechst 33342 neurotoxicity comes from experiments (not shown) demonstrating that staining of the nucleus with these nuclear acid binding dyes is not detectable until at least 10 min after dye application.

\section{Mitochondrial DNA}

Another possible target of nucleic acid binding dyes is mitochondrial DNA. Mitochondria play essential roles in producing the energy required for normal neurite homeostasis. It seems logical that inhibition of mitochondrial DNA could impair energy metabolism, leading to rapid neurite dysfunction. However, the rapidity of Hoechst 33342induced changes in neurite morphology is inconsistent with energy failure because of mitochondrial genomic inhibition, which would require rapid turnover of mitochondrial gene products. In addition, our time-course studies indicate that, although acute exposure to high concentrations of Hoechst $(60 \mu \mathrm{M})$ causes a transient decrease in mitochondrial potential, there is no long-term progressive disruption which parallels neurite instability. Furthermore, acute exposure to lower Hoechst concentrations that cause neurite fragmentation $(15 \mu \mathrm{M})$ do not decrease mitochondrial potential. This strongly suggests that mitochondria are functional during the time that nucleic acid binding compounds are disrupting neurites, although we cannot rule out the possibility that a transient depolarization of mitochondria plays a destabilizing role.

\section{RNA}

We present evidence that RNA may be an important target of nucleic acid binding compounds. RNA within neurites has been described recently, and is thought to be transported long distances based on cis-acting sequences encoded mostly in the $3^{\prime}$ untranslated region. Local translation of this RNA has been demonstrated in dendrites (reviewed Steward 2003) and in axons (reviewed Piper 2004), and plays a role in growth cone collapse ( $\mathrm{Wu} 2005)$. Ribosomal RNA is also localized to neurites and is undoubtedly required for translation of this RNA. While some of this RNA appears to be localized in foci that are traceable with dyes such as SYTO14 (Knowles et al. 1996), a large number of studies have also demonstrated broadly distributed localization depending on the RNA species (Mohr 2000; Wu 2005). Therefore, current information suggests that as a whole, RNA is diffusely localized throughout the neurite. This matches well with the diffuse distribution of neurite breakpoints we describe. 
Most nucleic acid binding compounds are able to bind to RNA as well as DNA, some with affinities greater for RNA (Wilson et al. 1993; Knowles et al. 1996; Dassonneville et al. 1997). Many of these agents selectively bind to doublestranded RNA with significantly higher affinity compared with single-stranded RNA. Experiments demonstrating that RNaseV1 causes neurotoxic effects comparable with those induced by Hoechst 33342 suggest that dsRNA is the principal target in Hoechst 33342 neurotoxicity and indicate that dsRNA may play an important role in neurite homeostasis. Two observations suggest that the neurotoxic effects of RNaseV1 are mediated by its RNA degrading function: (i) known inhibitors of RNaseV1 attenuate its neurotoxic effects on cortical neurons; and (ii) RNaseV1 neurotoxicity is sensitive to heat. We cannot yet exclude the possibility that minor contaminants within the RNaseV1 preparation used in these studies that are also sensititve to heparin, tRNA, and heat inactivation may be responsible for the enzyme's neurotoxic activity. Phospholipase A2 from cobra venom can contaminate preparation of RNaseV1; however, heparin increases the activity of phospholipases (Patel et al. 1997) and phospholipase A2 is not known to be affected by tRNA. Heparin is known to inhibit complement-activating toxins from cobra venom (Edens et al. 1994); however, our experiments were performed in serum-free media, which lack complement. We postulate that the RNaseV1 protein is cell permeable or that the RNA target that mediates neurite morphology is extracellular. The former possibility is more likely, and not necessarily surprising as many proteins, particularly in venom extracts (the source of the RNaseV1 used in our studies) are capable of crossing the plasma membrane. This is supported in experiments showing that RNaseV1 diminishes ribosomal RNA content within cells in a time course that precedes membrane permeability to propidium iodide, a molecule much smaller than RNaseV1 which is commonly used as a marker of cell death. Conclusive demonstration that RNaseV1 is able to cross the cytoplasmic membrane will require development of specific antisera which are not yet available.

The selectivity of RNaseV1 for double-stranded RNA in vitro suggests that the putative RNA target in neurons has a significant secondary structure. The possible known RNA targets include tRNA, rRNA, mRNA, ribonuclear proteins and microRNAs. Although microRNAs are single stranded, processing of microRNA precursors requires double-stranded RNA (Hutvagner and Zamore 2002). Targeting tRNA or rRNA would be predicted to impair protein synthesis within neurites. Because transient inhibition of protein synthesis by cycloheximide fails to cause neurite fragmentation, it is more likely that mRNA or structural RNAs that are not integrally involved in protein synthesis are targeted by RNaseV1 and the nucleic acid binding dyes. The rapidity of morphological changes seen in our experiments also strongly suggests that RNA may play a structural role within the neurite, as opposed to a role in protein synthesis. Recent data has demonstrated that spreading initiation centers, novel cytoskeletal structures present early in cell spreading, are highly enriched in RNA binding proteins and ribosomal RNA (de Hoog et al. 2004). Taken together with our experiments, these studies suggest a novel role for RNA in cytoskeletal maintenance and dynamic modulation.

We note that this mechanism does not apply to all classes of drugs that interfere with nucleic acid functions (e.g. topoisomerase inhibitors or dideoxy nucleoside analogues). However, considering the wide variety of potential RNA structures that could exist in neurites, it is possible that even drugs without a known affinity for nucleic acids, could act on neurons through specific RNA binding. For example, AZT, a specific inhibitor of HIV reverse transcriptase which causes neuropathy has been shown to bind to RNA (Ahmed Ouameur et al. 2004). In further support that RNA could be a general target of neurotoxic compounds, we note that several drugs, including streptomycin (Wallace and Schroeder 1998), spectinomycin (Thom and Prescott 1997), and tobramycin (Hermann and Westhof 1999), have been shown to bind to specific RNA sequences with high affinity.

In conclusion, nucleic acid binding agent-induced neurotoxicity through non-nuclear paths provides an alternative mechanism for neurite damage which is independent of excitotoxicity and free radicals and is possibly mediated by interactions with RNA. The precise mechanism of damage to neurites may have important implications regarding the cause and treatment of neuropathies associated with nucleic acid binding drugs. Finally, from a practical point of view, these studies indicate that cell permeable nucleic acid binding agents should be used with caution in neuronal culture studies.

\section{Acknowledgements}

This work was supported by grants from the National Institutes of Health (NS041342 to MMW and NS046649 to PJL) and a Burroughs Wellcome Fund Career Award in Biomedical Sciences (MMW).

\section{References}

Ahmed Ouameur A., Marty R., Neault J. F. and Tajmir-Riahi H. A. (2004) AZT binds RNA at multiple sites. DNA Cell Biol. 23, 783788.

Brewer G. J. (1995) Serum-free B27/neurobasal medium supports differentiated growth of neurons from the striatum, substantia nigra, septum, cerebral cortex, cerebellum, and dentate gyrus. J. Neurosci. Res. 42, 674-683.

Chen J. C., Zhang X., Singleton T. P. and Kiechle F. L. (2004) Mitochondrial membrane potential change induced by Hoechst 33342 in myelogenous leukemia cell line HL-60. Ann. Clin. Lab. Sci. 34, 458-466. 
Cui L., Locatelli L., Xie M. Y. and Sommadossi J. P. (1997) Effect of nucleoside analogs on neurite regeneration and mitochondrial DNA synthesis in PC-12 cells. J. Pharmacol. Exp. Ther. 280, $1228-1234$.

Dalakas M. C. (2001) Peripheral neuropathy and anti-retroviral drugs. J. Peripher. Nerv. Syst. 6, 14-20.

Dassonneville L., Hamy F., Colson P., Houssier C. and Bailly C. (1997) Binding of Hoechst 33258 to the TAR RNA of HIV-1. Recognition of a pyrimidine bulge-dependent structure. Nucleic Acids Res. 25, $4487-4492$.

De Clercq E. (2002) New developments in anti-HIV chemotherapy. Biochim. Biophys. Acta 1587, 258-275.

Druker B. J., Rosenthal D. S. and Canellos G. P. (1989) Chlorambucil, vinblastine, procarbazine, and prednisone. An effective but less toxic regimen than MOPP for advanced-stage Hodgkin's disease. Cancer 63, 1060-1064.

Dubinsky R. M., Yarchoan R., Dalakas M. and Broder S. (1989) Reversible axonal neuropathy from the treatment of AIDS and related disorders with $2^{\prime}, 3^{\prime}$-dideoxycytidine (ddC). Muscle Nerve 12, 856-860.

Edens R. E., Linhardt R. J., Bell C. S. and Weiler J. M. (1994) Heparin and derivatized heparin inhibit zymosan and cobra venom factor activation of complement in serum. Immunopharmacology 27, $145-153$.

Fleming R. A. (1997) An overview of cyclophosphamide and ifosfamide pharmacology. Pharmacotherapy 17, 146S-154S.

Frisk P., Stalberg E., Stromberg B. and Jakobson A. (2001) Painful peripheral neuropathy after treatment with high-dose ifosfamide. Med. Pediatr. Oncol. 37, 379-382.

Gould T. J. and Bickford P. C. (1994) The effects of chronic treatment with $N$-tert-butyl- $\alpha$-phenylnitrone on cerebellar noradrenergic receptor function in aged F344 rats. Brain Res. 660, 333-336.

Hasbani M. J., Hyrc K. L., Faddis B. T., Romano C. and Goldberg M. P. (1998) Distinct roles for sodium, chloride, and calcium in excitotoxic dendritic injury and recovery. Exp. Neurol. 154, 241-258.

Hermann T. and Westhof E. (1999) Docking of cationic antibiotics to negatively charged pockets in RNA folds. J. Med. Chem. 42, 1250-1261.

de Hoog C. L., Foster L. J. and Mann M. (2004) RNA and RNA binding proteins participate in early stages of cell spreading through spreading initiation centers. Cell 117, 649-662.

Hutvagner G. and Zamore P. D. (2002) A microRNA in a multipleturnover RNAi enzyme complex. Science 297, 2056-2060.

Imrie K. R., Couture F., Turner C. C., Sutcliffe S. B. and Keating A. (1994) Peripheral neuropathy following high-dose etoposide and autologous bone marrow transplantation. Bone Marrow Transplant 13, 77-79.

Job C. and Eberwine J. (2001) Localization and translation of mRNA in dendrites and axons. Nat. Rev. Neurosci. 2, 889-898.

Kiechle F. L. and Zhang X. (2002) Apoptosis: biochemical aspects and clinical implications. Clin. Chim. Acta 326, 27-45.

Keswani S. C., Chander B., Hasan C., Griffin J. W., McArthur J. C. and Hoke A. (2003) FK506 is neuroprotective in a model of antiretroviral toxic neuropathy. Ann. Neurol. 53, 57-64.

Knowles R. B., Sabry J. H., Martone M. E., Deerinck T. J., Ellisman M. H., Bassell G. J. and Kosik K. S. (1996) Translocation of RNA granules in living neurons. J. Neurosci. 16, 7812-7820.

Kundu G. C., Schullek J. R. and Wilson I. B. (1994) The alkylating properties of chlorambucil. Pharmacol. Biochem. Behav. 49, 621624.

Lein P. J. and Higgins D. (1989) Laminin and a basement membrane extract have different effects on axonal and dendritic outgrowth from embryonic rat sympathetic neurons in vitro. Dev. Biol. 136, 330-345.
Lockard R. E. and Kumar A. (1981) Mapping tRNA structure in solution using double-strand-specific ribonuclease V1 from cobra venom. Nucleic Acids Res. 9, 5125-5140.

Lowman H. B. and Draper D. E. (1986) On the recognition of helical RNA by cobra venom V1 nuclease. J. Biol. Chem. 261, 53965403.

Mahalakshmi Y. V., Jagannadham M. V. and Pandit M. W. (2000) Ribonuclease from cobra snake venom: purification by affinity chromatography and further characterization. IUBMB Life 49, 309316.

Martin D. P., Wallace T. L. and Johnson E. M. Jr (1990) Cytosine arabinoside kills post-mitotic neurons in a fashion resembling trophic factor deprivation: evidence that a deoxycytidine-dependent process may be required for nerve growth factor signal transduction. J. Neurosci. 10, 184-193.

Meresse P., Dechaux E., Monneret C. and Bertounesque E. (2004) Etoposide: discovery and medicinal chemistry. Curr. Med. Chem. 11, 2443-2466.

Mohr E. and Richter D. (2000) Axonal mRNAs: functional significance in vertebrates and invertebrates. J. Neurocytol. 29, 783-791.

Morris E. J. and Geller H. M. (1996) Induction of neuronal apoptosis by camptothecin, an inhibitor of DNA topoisomerase-I: evidence for cell cycle-independent toxicity. J. Cell Biol. 134, 757-770.

Nieminen A. L., Saylor A. K., Tesfai S. A., Herman B. and Lemasters J. J. (1995) Contribution of the mitochondrial permeability transition to lethal injury after exposure of hepatocytes to $t$-butylhydroperoxide. Biochem. J. 307, 99-106.

Ozols R. F. and Young R. C. (1985) High-dose cisplatin therapy in ovarian cancer. Semin. Oncol. 12, 21-30.

Park J. S., Bateman M. C. and Goldberg M. P. (1996) Rapid alterations in dendrite morphology during sublethal hypoxia or glutamate receptor activation. Neurobiol. Dis. 3, 215-227.

Park D. S., Morris E. J., Stefanis L., Troy C. M., Shelanski M. L., Geller H. M. and Greene L. A. (1998) Multiple pathways of neuronal death induced by DNA-damaging agents, NGF deprivation, and oxidative stress. J. Neurosci. 18, 830-840.

Patel S. R., Forman A. D. and Benjamin R. S. (1994) High-dose ifosfamide-induced exacerbation of peripheral neuropathy. J. Natl Cancer Inst. 86, 305-306.

Patel H. V., Vyas A. A., Vyas K. A., Liu Y. S., Chiang C. M., Chi L. M. and $\mathrm{Wu}$ W. (1997) Heparin and heparan sulfate bind to snake cardiotoxin. Sulfated oligosaccharides as a potential target for cardiotoxin action. J. Biol. Chem. 272, 1484-1492.

Piper M. and Holt C. (2004) RNA translation in axons. Annu. Rev. Cell. Dev. Biol. 20, 502-503.

Povirk L. F. and Shuker D. E. (1994) DNA damage and mutagenesis induced by nitrogen mustards. Mutat. Res. 318, 205-226.

Resar L. M., Phillips P. C., Kastan M. B., Leventhal B. G., Bowman P. W. and Civin C. I. (1993) Acute neurotoxicity after intrathecal cytosine arabinoside in two adolescents with acute lymphoblastic leukemia of B-cell type. Cancer 71, 117-123.

Senger D. L. and Campenot R. B. (1997) Rapid retrograde tyrosine phosphorylation of trkA and other proteins in rat sympathetic neurons in compartmented cultures. J. Cell Biol. 138, 411421.

Slapak C. A., Fine R. L. and Richman C. M. (1985) Differential protection of normal and malignant human myeloid progenitors (CFU-GM) from Ara-C toxicity using cycloheximide. Blood 66, 830-834.

Stefanis L., Park D. S., Friedman W. J. and Greene L. A. (1999) Caspase-dependent and -independent death of camptothecin-treated embryonic cortical neurons. J. Neurosci. 19, 6235-6247.

Steward O. and Schuman E. M. (2003) Compartmentalized synthesis and degradation of proteins in neurons. Neuron 40, 347-359. 
Sturgess N. C., Rustad A., Fonnum F. and Lock E. A. (2000) Neurotoxic effect of L-2-chloropropionic acid on primary cultures of rat cerebellar granule cells. Arch. Toxicol. 74, 153-160.

Thom G. and Prescott C. D. (1997) The selection in vivo and characterization of an RNA recognition motif for spectinomycin. Bioorg. Med. Chem. 5, 1081-1086.

Wallace T. L. and Johnson E. M. Jr (1989) Cytosine arabinoside kills post-mitotic neurons: evidence that deoxycytidine may have a role in neuronal survival that is independent of DNA synthesis. J. Neurosci. 9, 115-124.

Wallace S. T. and Schroeder R. (1998) In vitro selection and characterization of streptomycin-binding RNAs: recognition discrimination between antibiotics. RNA 4, 112-123.

Wang D. and Lippard S. J. (2005) Cellular processing of platinum anticancer drugs. Nat. Rev. Drug Discov. 4, 307-320.

Ward M. W., Rego A. C., Frenguelli B. G. and Nicholls D. G. (2000) Mitochondrial membrane potential and glutamate excitotoxicity in cultured cerebellar granule cells. J. Neurosci. 20, 72087219.

Wilson W. D., Ratmeyer L., Zhao M., Strekowski L. and Boykin D. (1993) The search for structure-specific nucleic acid-interactive drugs: effects of compound structure on RNA versus DNA interaction strength. Biochemistry 32, 4098-4104.

Wu K. Y., Hengst U., Cox L. J., Macosko E. Z., Jeromin A., Urquhart E. R. and Jaffrey S. R. (2005) Local translation of RhoA regulates growth cone collapse. Nature 436, 1020-1024.

Xu Y., Traystman R. J., Hurn P. D. and Wang M. M. (2003) Neuritelocalized estrogen receptor- $\alpha$ mediates rapid signaling by estrogen. J. Neurosci. Res. 74, 1-11.

Zhang X. and Kiechle F. L. (1997) Hoechst 33342-induced apoptosis in BC3H-1 myocytes. Ann. Clin. Lab. Sci. 27, 260-275.

Zhang X., Chen J., Davis B. and Kiechle F. (1999) Hoechst 33342 induces apoptosis in HL-60 cells and inhibits topoisomerase I in vivo. Arch. Pathol. Lab. Med. 123, 921-927. 